\title{
The perceived barriers to insulin therapy among type 2 diabetic patients
}

\author{
Amin Hussein ${ }^{1}$, Arafa Mostafa ${ }^{2}$, Alnomi Areej ${ }^{1}$, Al-muteb Mona ${ }^{1}$, \\ Alduaiji Shimaa ${ }^{1}$, Al-Gazlan Najd ${ }^{1}$, Alnemari Futoon ${ }^{1}$
}

1. King Saud University, Family and Community Medicine

2. King Saud University, Chair of Cancer Research

\begin{abstract}
:
Background: Problems may arise with insulin treatment, due to patients' perspective towards it leading to refusal.

Objectives: To evaluate diabetic patients' refusal towards insulin therapy, and to assess patients' perception and perceived barriers towards insulin.

Methods: A cross-sectionalstudy, where type 2 diabetics participated in the study during a period, February through March 2017. They were interviewed in person by a questionnaire including three sections; socio-demography, medical history and a health belief model, comprising barriers to use insulin. Five points Likert scale was used to measure patients' perception and barriers towards insulin therapy.

Results: One fourth (24.4\%) of the diabetic patients refused insulin. Among the controlled group, 34.4\% refused insulin, while $21 \%$ refused insulin among the uncontrolled group. The study showed different barriers towards insulin therapy, including fear of injection, pain, insulin injection needs help from others, fear of hypoglycaemia and embarrassment.

Conclusion: Diabetics showed a negative attitude towards insulin therapy due to social and psychological factors. The results necessitate the development of a strategy to address problems related with a reluctance to initiate insulin and put a strategy to implement education and better interaction with diabetic team to the stigma from phobia from insulin use.
\end{abstract}

Keywords: Barriers to insulin therapy, type 2 diabetic patients.

DOI: https://dx.doi.org/10.4314/ahs.v19i1.39

Cite as: Hussein A, Mostafa A, Areej A, Mona A, Shimaa A, Najd A, et al. The perceived barriers to insulin therapy among type 2 diabetic patients. Afri Health Sci. 2019;19(1). 1638-1646. https:// dx.doi.org/10.4314/abs.v19i1.39

\section{Introduction}

All over the world, an estimated 382 million people are living with diabetes, and this number is expected to rise to 592 million by $2035^{1}$. The World Health Organization (WHO) has reported that Saudi Arabia ranks the second highest in the Middle East and is the seventh in the world for the rate of increasing number of diabetes cases. It is estimated that around 7 million of the Saudi population are diabetics and around 3 million have pre-diabetes.

\section{Corresponding author:}

Amin Hussein, King Saud University, Family and Community Medicine Email: hsmamin@gmail.com
Diabetes has approximately registered a ten-fold increase over the past three decades in Saudi Arabia ${ }^{2}$.

For the management of diabetes, there are various oral hypoglycemic drugs (OHDs) that are available worldwide. Recommendations for their use either as monotherapy or in combination with or without insulin are described in many of diabetes management guidelines including the American Diabetes Association (ADA) guidelines ${ }^{3}$.

Insulin is eventually required for control of diabetes when secondary failure of $\beta$-cells of pancreas occurs down the course of the disease. One of the main problems associated with insulin therapy is the delay in initiation of treatment up to complete refusal by the patient due to different perspectives and health beliefs. This results in many complications which inflicts a huge burden on the health care budget as well as economy of the country ${ }^{4}$.

There are many causes for refusal of insulin therapy by 
diabetics as well as several patient related factors for delay in insulin initiation. These factors have been studied by many researchers in Saudi Arabia in $2014^{5}$ as well as other countries such as Korea ${ }^{6}$, England and United States (US) $)^{6-8}$.

In 2014, it has been estimated that the prevalence of insulin refusal among type 2 diabetic patients in Saudi Arabia was $34.6 \% \%^{5}$. The refusal of insulin is a problem worldwide, not just in Saudi Arabia. A study conducted in Korea showed that insulin refusal rate was 33.6\% and patient-related factors for delay in insulin initiation included older age, shorter duration of diabetes and lower glycated haemoglobin (HBA1c $)^{6}$. The study conducted in London by Khan et al among Bangladeshi patients with poorly controlled type 2 diabetes showed that $20.3 \%$ refused to commence insulin therapy despite repeated counseling ${ }^{7}$ and in another study conducted by Karter et al in the US revealed that $35 \%$ refused insulin for many reasons ${ }^{8}$.

The aim of the current study was to measure the refusal rate of insulin therapy among type 2 diabetic patients in 2017, to assess their perception towards insulin therapy and enumerate the most significant barriers to refusal of insulin intake.

\section{Methods}

A cross-sectional study was conducted at the primary health care clinics in King Khaled University Hospital, Riyadh, Saudi Arabia, where patients with type 2 diabetes mellitus attending theclinics during the months of February and March 2017 were invited to participate in the study. The aim and rationale of the study were explained to each participant. An informed consent was signed by every patient included in the study. All type 1 diabetic patients, those below the age of 30 years and gestational diabetes have been excluded excluded from the study.

\section{Sampling:}

In order to calculate the sample size we hypothesized that $34.6 \%$ of Saudi type 2 diabetic patients refused insulin therapy based on a study conducted in $2014^{5}$. With a significance level of $95 \%(Z=1.96)$, a margin error of $5 \%$ $(\mathrm{d}=0.05)$ and by using the formula $\left(\mathrm{n}=\mathrm{Z}^{\wedge} 2 \mathrm{p}(1-\mathrm{p}) / \mathrm{d} 2\right)$, the minimal required sample size was estimated to be 348 with $10 \%$ non-response rate.

\section{Data collection:}

Trained personnel were used to interview patients and fill out a pre-prepared questionnaire. The questionnaire was divided into three sections: socio-demographic information, medical history and perceived barriers to use insulin. The section in questionnaire concerning insulin barriers has been adopted and modified from other studies ${ }^{5,6,7,8}$. A health belief model was constructed where five points Likert scale was used to measure patients' perception and barriers towards insulin therapy. The scale ranged from 'strongly agree' to 'strongly disagree'. The highest score was 5 and the lowest score was 1 . Fifteen statements were used to compose this scale. The sum of the factors within this scale ranged from 15 to 75 points. Data regarding HbA1c levels and any diabetic complications were retrieved from the patients' medical records.

\section{Pilot study:}

A pilot study was conducted for 10 participants to test the questionnaire feasibility and the reliability of Likert scale where krobach's alpha was $74.2 \%$.

\section{Statistical analysis:}

Data were analyzed using SPSS software, version 23 (SPSS Inc., Chicago, Illinois, USA). The categorical variables in the study were presented as percentages. The chi-square test was used for comparison. Analysis was carried out at a significance level of $0.05(\mathrm{p}<0.05)$.

The study was approved by the Institutional Review Board (IRB) of the College of Medicine and performed in accordance with the ethical standards.

\section{Results:}

The study included 402 type 2 diabetic patients, where 152 $(37.8 \%)$ were males. Their ages ranged from 30 to over 70 years. More than one third of the patients $(37.8 \%)$ were in the age group 51-60 years. Nearly, one-third (32.1\%) were uneducated.

Only $23.9 \%$ of population study had controlled diabetes $(\mathrm{HbA} 1 \mathrm{c} \leq 7)$ while the majority $(76.1 \%)$ were uncontrolled. Among the controlled group, 63 patients $(65.6 \%)$ accepted insulin therapy while 33 patients $(34.4 \%)$ refused it. On the other hand, $79 \%$ of the uncontrolled group accepted insulin therapy and 21\% refused. The difference between the two groups was statistically significant $(p=0.008)$.

Among the participants enrolled, 242 (60.2\%) were using OHDs while the rest 160 (39.8\%) were already on insulin. Concerning the acceptance of insulin use, 98 patients $(24.4 \%)$ refused insulin injections. None of elements of the socio-demographic data was statistically significantly different between the two groups (Table 1). 
Table 1: Accept or refuse taking insulin according to patients' socio-demagraphic data.

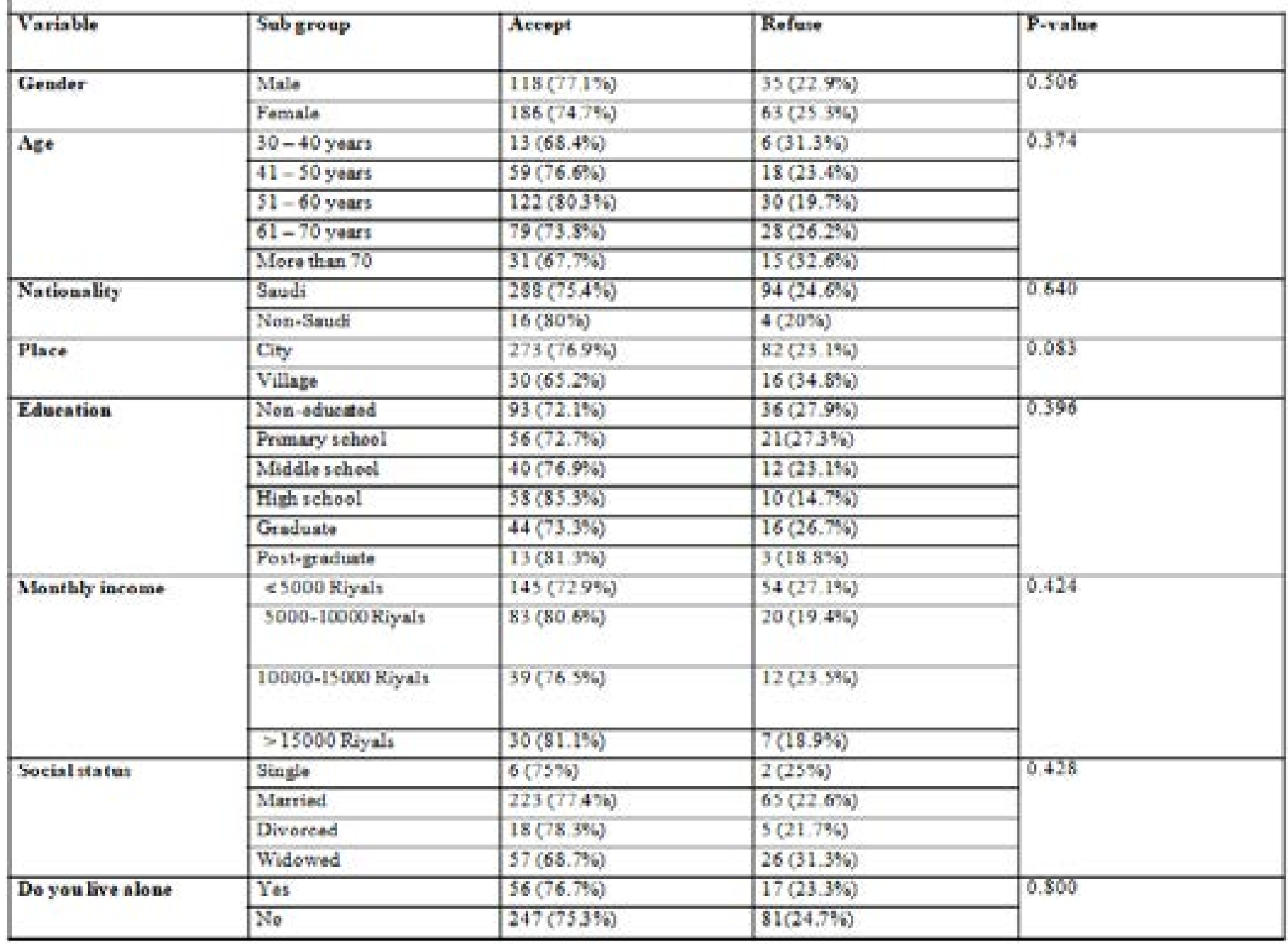

The perceived barriers to insulin therapy amongst all patients are shown in Table 2. The mean of the items' sum was $46.4+8.7$ which indicated poor perception towards insulin therapy. It is worth mentioning that most of the patients $(87.6 \%)$ take treatment information from their physicians, yet, refusal rate was still high. After combining the two categories of 'strongly agree' and 'agree', five statements represented the most prominent perceived barriers amongst patients on OHDs in comparison with those on insulin therapy. The statements were: (1) using insulin means reaching end-stage diabetes, (2) using insulin means failure of a diabetic to take care of his/her health, (3) using insulin can cause anxiety because I don't know the right way to inject it, (4) injecting insulin requires the help of others and finally, (5) fear of injections. In addition, two social factors have been recognized as significant barriers to insulin therapy, namely the restriction of daily life activities and feeling different from others. 


\begin{tabular}{|c|c|c|c|c|}
\hline Tatamen to toks isalis & Babsoup & Ftiets os hils & Fones of Lavin & Praler \\
\hline \multirow{5}{*}{ 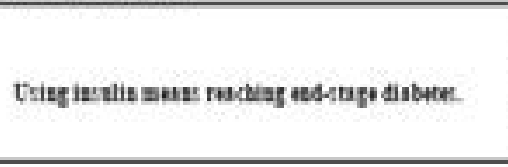 } & worowom & 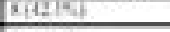 & 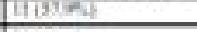 & \multirow{5}{*}{ ini } \\
\hline & Guref & DIm:4hy & gasmen & \\
\hline & Gutat & Pरकाष & DIrIses & \\
\hline & yㅗ & Pootan & Eilonu & \\
\hline & Dniedy you & सestege & 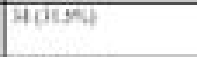 & \\
\hline \multirow{5}{*}{ Trisg isedis reerict daily life scenite. } & Sondy Drape & मसमाश्सा & सतिक्षण & \multirow{5}{*}{$\cos i$} \\
\hline & Owaser & Wकासी & $37+654$ & \\
\hline & Noval & 3 mat & DEz- & \\
\hline & Aym= & miptivel & कासे & \\
\hline & unespy tyue & inesent & 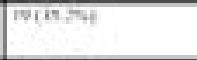 & \\
\hline \multirow{5}{*}{ Vist ia:alis cases snere bypaflyceain. } & 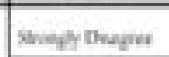 & Prisuan & परिस्स & \multirow{5}{*}{ tos } \\
\hline & Dougen & संख़का & श्रतियक्य & \\
\hline & Nonal & Pिजका & $4012 \pi$ & \\
\hline & Ayou & nomitist & sicisnis & \\
\hline & hanght Ayos & $\sin 20$ & pitunis & \\
\hline \multirow{5}{*}{ Vrisg iasalis ansas failert of taliog cart of vanelf } & 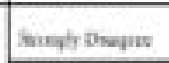 & CP(xis) & Fासका & \multirow{5}{*}{00001} \\
\hline & Deapen & शिख्यात्र & 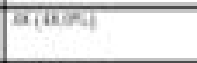 & \\
\hline & Nutal & समश्रास & सम्समा & \\
\hline & Yye & v(rome & काणिएक्या & \\
\hline & Poneeth low & $300 \mathrm{non}$ & $1823 \pi+4$ & \\
\hline \multirow{5}{*}{ Isvelis iecrases boty veighe } & Sough thepes & miens & 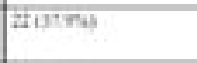 & \multirow{5}{*}{-60001} \\
\hline & Despir & somentes & इत्रका & \\
\hline & Nounai & 6rast & P(NकW & \\
\hline & syou & सकाजिए & 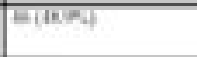 & \\
\hline & someph lyou & 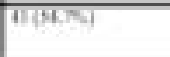 & मीक्षण & \\
\hline \multirow{5}{*}{ 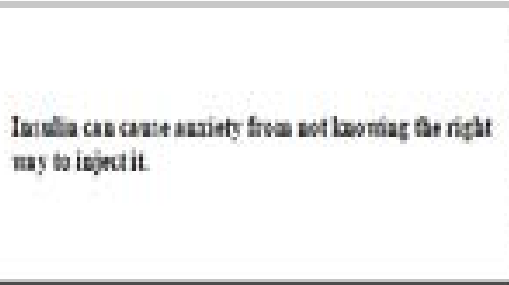 } & 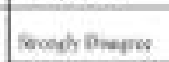 & incoesi & 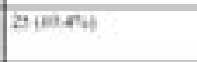 & \multirow{5}{*}{-60001} \\
\hline & Dewper & ateatsis & seotsing & \\
\hline & Xoneal & worisi & Erdoswh & \\
\hline & $A y=$ & aptiny & mon: & \\
\hline & 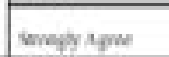 & 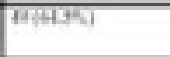 & निएक्ष & \\
\hline \multirow{5}{*}{ Injectist is:alis requirn tab belp of often. } & sompl Deque & 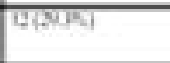 & 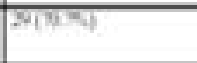 & \multirow{5}{*}{$-\infty=001$} \\
\hline & Dowars & 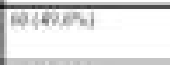 & Mाइस्रप & \\
\hline & Nowal & $924 \pi$ & wisani & \\
\hline & $\mathrm{Men}$ & mantas & arisoment & \\
\hline & money tyee & मालm 501 & सing & \\
\hline
\end{tabular}


Table 2: Perteptions of patients touard issulin therapy- (continued)

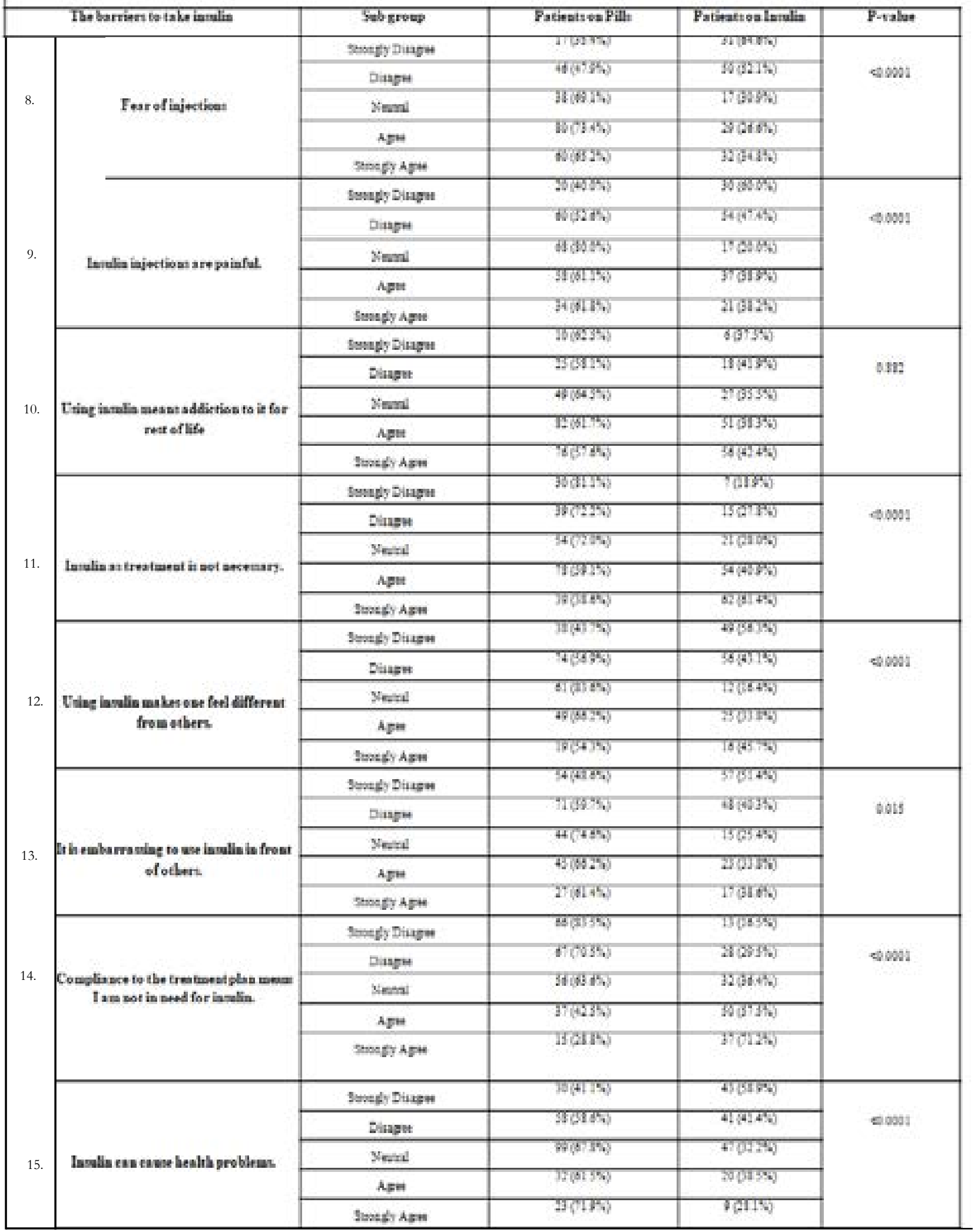


During the conduction of the study, special interest was directed towards nephropathy as the main complication of diabetes. Of the entire study group, 118 (29.9\%) patients had documented nephropathy as a complication while $276(70 \%)$ did not suffer from diabetic nephropathy. Within the nephropathy group, 93 (78.8\%) accepted insulin therapy while the remaining $25(21.2 \%)$ had refused (Table 3). No statistically significant difference was detected between the groups with or without nephropathy, $(p=0.336)$.
Regarding the control of diabetes, most of the uncontrolled diabetic patients, 241 (79\%), accepted insulin therapy versus $64(21 \%)$ uncontrolled patients who refused to receive insulin; the difference was statistically significant, $(\mathrm{p}=0.008)($ Table 3).

Hypertension was reported in 248 (61.7\%) patients, hyperlipidemia in $256(63.7 \%)$ patients, cardiovascular disease in $68(16.9 \%)$ patients and 88 patients $(21.9 \%)$ had other chronic diseases (Figure 1). It was found that only hyperlipidemia showed a statistically significant difference $(p=0.006)$ regarding acceptance or refusal of insulin injections.

Table 3: Accept or refuse taking insulin according to the control of diabetes and nephropathy as a complication.

\begin{tabular}{|c|c|c|c|c|}
\hline Variable & Sub group & $\begin{array}{c}\text { Accept to use } \\
\text { insulin }\end{array}$ & $\begin{array}{c}\text { Refuse to use } \\
\text { insulin }\end{array}$ & P-value \\
\hline HbA1C & Controlled & $63(65.6 \%)$ & $33(34.4 \%)$ & 0.008 \\
& Uncontrolled & $241(79 \%)$ & $64(21 \%)$ & \\
\hline \multirow{2}{*}{ Nephropathy } & Yes & $93(78.8 \%)$ & $25(21.2 \%)$ & 0.336 \\
& No & $205(74.3 \%)$ & $71(25.7 \%)$ & \\
\hline
\end{tabular}

\section{Accept or refuse taking insulin according to patient chronic disease}

300

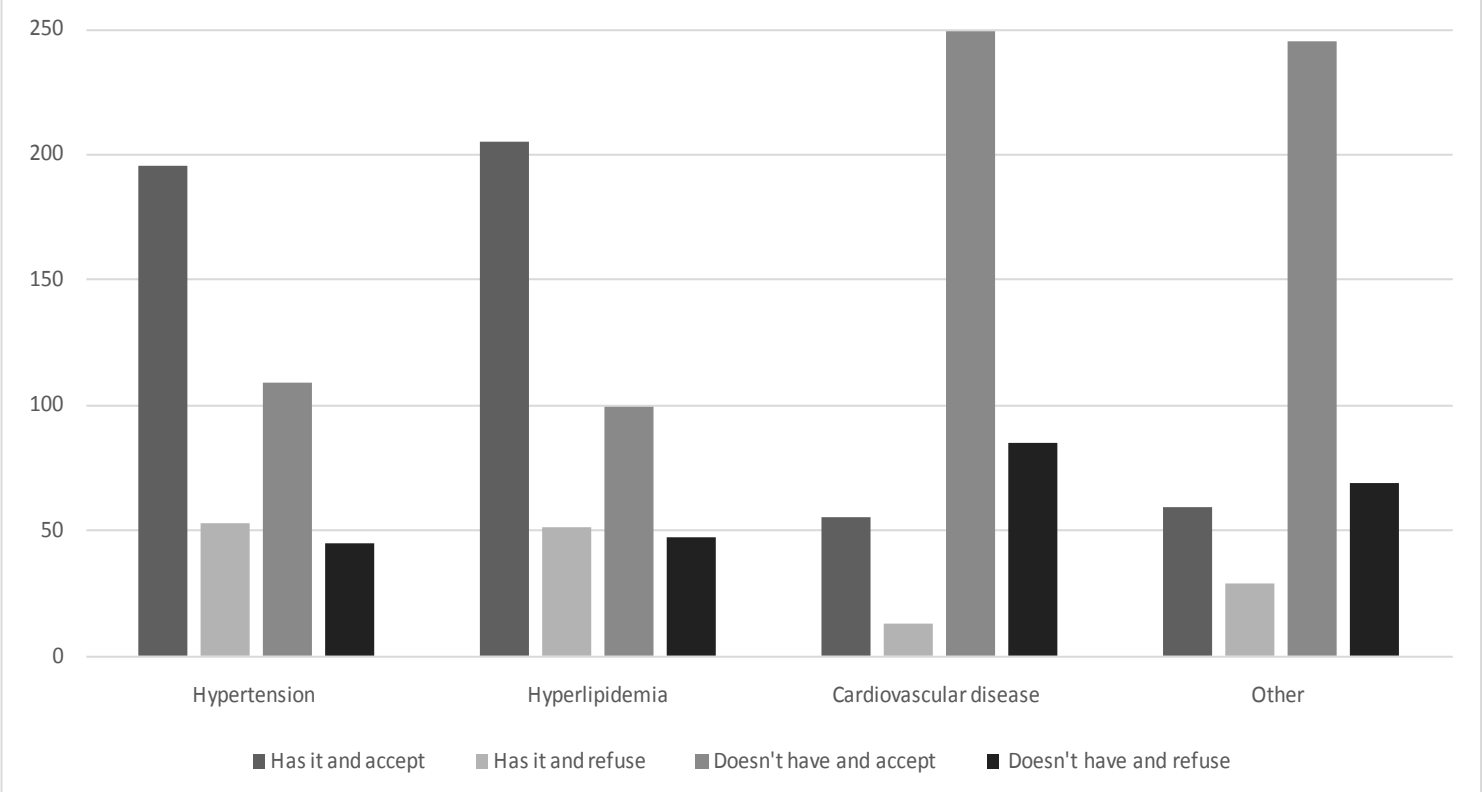

Figure 1 


\section{Discussion}

Guidelines for management of diabetes recommend the use of OHDs as monotherapy or as combination therapy with or without insulin. The oral hypoglycemic drugs are often initially successful in lowering the glycated hemoglobin level but unfortunately, alone, they are unable to maintain normal levels of HbA1c on the long run. Appropriate timing for initiation of insulin therapy is recommended in patients who are uncontrolled, as it reduces diabetes-related complications, improves the cardiovascular profile and helps preserve $\beta$-cell function for a longer duration than OHDs alone?

The percentage of diabetics who refused insulin therapy in the current study is still high (25\%), although it has dropped compared to a previous study done in Saudi Arabia in $2014(34.6 \%)^{5}$. In comparison with other countries; our figure is much lower than the refusal rates reported in Iran $(77 \%)^{10}$, Malaysia $(74.2 \%)^{11}$ and Singapore $(70 \%)^{12}$. However, it is quite close to the figure reported in the US $(28.2 \%)^{13}$.The great discrepancy between results across different countries could be attributed to the different inclusion criteria. In our study, we included type 2 diabetic patients only whether on OHDs or insulin therapy and we excluded type 1 diabetics.

None of the socio-demographic factors were found to be significantly different between the groups in the current study, which is different from the conclusions reached in other studies such as in the US where females were found to be less likely to accept insulin therapy ${ }^{13}$. Also, in Malaysia, the level of education had a significant impact on the willingness to use insulin ${ }^{11}$ as well as in South Africa ${ }^{14}$. Participants who had controlled levels of HbA1c were more reluctant to use insulin than those with uncontrolled levels; this finding was supported by previous studies conducted in Singapore ${ }^{12}$ and Korea ${ }^{15}$. Patients with controlled $\mathrm{HbA1c}$ believe that they do not require insulin therapy. These results are opposite to the work presented by Hosomura et al that discovered a higher insulin therapy refusal rate among uncontrolled diabetics ${ }^{16}$. The study by Khan et al in London on Bangladeshi patients showed that informing patients that they require insulin leads to the false belief of being in a late stage of the disease with imminent, premature death. Other patients in the same study had fear of hypoglycemia, weight gain and loss of independence ${ }^{7}$. In spite of getting information about diabetes from their physicians, the majority of participants in our study had many misconceptions, whether they were OHDs- or insulin-users ${ }^{12}$. Those who were using OHDs only tended to refuse insulin therapy more strongly than the insulin using group.

Participants in our study in both groups (OHDs- and insulin-users) showed a negative attitude and poor perception towardsinsulin therapy. Certain statements have been chosen as stronger barriers to insulin therapy than others. The most prominent reasons for refusal were fear of injection, the need to be compliant with the treatment plans, concerns about way of life and future and finally, the perception that they reached an end-stage in the disease course. Similar reasons have been mentioned in earlier studies and therefore, researchers stated that it was preferable to introduce insulin to the treatment plan early in the course of the disease so that insulin would not be perceived as being a treatment for end-stage patients ${ }^{10}$. Other barriers that were perceived by patients include weight gain, hypoglycemia and other health problems. These barriers were also reported by other studies as some of the main factors that discourage patients to use insulin ${ }^{7,16}$.

Another major concern that was mentioned by insulin naïve diabetics is the awkwardness of being falsely recognized by the community as drug addicts due to the continuous use of syringes and vials. Patients with prior insulin experience had fewer barriers arising from injection-related issues and worried less about the burden of insulin dose increments than did insulin-naive patients ${ }^{17}$. In the current study, concerns about the impact of insulin injections on the participants' daily life activities were one of the significant social barriers mentioned regarding the intake of insulin. Restriction of daily life activities and feeling different from others were also found to be important by other studies ${ }^{11,13,15,19,20}$. Regarding complications of diabetes and its impact on insulin therapy, most of the patients suffering from nephropathy had accepted insulin. There are no reports in the literature to support or refute this finding or reveal any relation between diabetes complications and the patients' attitude towards insulin. Amongst different comorbidities, the only one that was statistically significant between the two groups was the presence of hyperlipidemia. Dyslipidaemic patients tended to accept insulin therapy more readily than other group.

Facing the stigma of diabetes has become a must. We need to change the behavioral goals and eliminate certain 
feelings associated with the disease and its treatment such as sense of personal failure, low self-esteem, phobia from insulin injections and the negative impact of insulin on social life and work. The prevalence of diabetes mellitus in Saudi Arabia has been increasing during the past thirty years and the rate of insulin therapy refusal is still high, even after decreasing from $34 \%$ in 2014 to $25 \%$ in our current study. Such rate is related to the negative attitude and poor perception of diabetic patients towards insulin therapy because of numerous social and psychological barriers $^{18}$. Exploring patients' worries and beliefs about diabetes and insulin is crucial to support physicians in delivering patient-centered care. Educating patients about the benefits of insulin therapy and the proper way of administration is necessary to make patients accept insulin treatment more readily. This could be achieved through attending support groups consisting of insulin users together with teaching pills-only users how to deal with complications related to insulin use such as hypoglycemia and weight gain.

\section{Limitation of the study:}

The main limitation of this study was the lower number of male diabetic patients as the data collectors were females which posed some difficulty in accessing the male clinics. Enrolling a larger number of patients by recruiting other hospitals and different health sectors will certainly provide a more accurate insight on all possible barriers perceived by patients to insulin therapy.

\section{Acknowledgments:}

We acknowledge the Research Chair, Deanship of Scientific Research in King Saud University for supporting the research.

\section{Conflict of interest}

None declared.

\section{References}

1. International Diabetes Federation. https://www.idf. org/e-library/.../diabetes-atlas/13-diabetes-atlas-seventh-edition.html. IDF Diabetes Atlas $7^{\text {th }}$ Edition (2015).

2. Al Dawish MA, Robert AA, Braham R, Al Hayek AA, Al Saeed A, Ahmed RA, Al Sabaan FS. Diabetes Mellitus in Saudi Arabia: A Review of the Recent Literature. Curr Diabetes Rev. 2016; 12(4):359-368.

3. American Diabetes Association. Standards of Medical Care in Diabetes. Diabetes. 2017; 40(Suppl. 1).
4. Robert A, Al Dawish M, Braham R, Musallam M, Al Hayek A, Al Kahtany N. Type 2 Diabetes Mellitus in Saudi Arabia: Major Challenges and Possible Solutions. Current Diabetes Reviews. 2016; 12(999):1-1.

5. Batais, MSchantter P. Prevalence of unwillingness to use insulin therapy and its associated attitudes amongst patients with Type 2 diabetes in Saudi Arabia. Primary Care Diabetes. 2016; 10(6):415-424.

6. Kim SG, Kim NH, Ku BJ, Shon HS, Kim DM, Park TS, Kim YS, Kim IJ, Choi DS. Delay of insulin initiation in patients with type 2 diabetes mellitus inadequately controlled with oral hypoglycemic agents (analysis of patient- and physician-related factors): A prospective observational DIPP-FACTOR study in Korea. J Diabetes Investig. 2017; 8(3):346-353.

7. Khan H, Lasker S. S, Chowdhury T. A. Prevalence and reasons for insulin refusal in Bangladeshi patients with poorly controlled Type 2 diabetes in East London. Diabetic Medicine. 2008; 25(9): 1108-1111.

8. Karter AJ, Subramanian U, Saha C, et al. Barriers to insulin initiation: the translating research into action for diabetes insulin starts project. Diabetes Care. 2010; 33(4):733-5.

9. Inzucchi SE, Bergenstal RM, Buse JB, et al. Management of hyperglycemia in type 2 diabetes: a patient-centered approach: position statement of the American Diabetes Association (ADA) and the European Association for the Study of Diabetes (EASD). Diabetes Care. 2012; 35: 1364-1379.

10. Anari AG, Fazaelipoor Z, Mohammadi SM. Insulin Refusal in Iranian Patients with Poorly Controlled Type 2 Diabetes Mellitus. Acta Medica Iranica. 2013; 51(8): 567571.

11. Tan WL, Asahar SF, Harun NL. Insulin therapy refusal among type II diabetes mellitus patients in Kubang Pasu district, the state of Kedah, Malaysia. Singapore Med J. 2015; 56(4):224-7.

12. Wong S, Lee J, Ko Y, Chong MF, Lam CK, Tang WE. Perceptions of insulin therapy amongst Asian patients with diabetes in Singapore. Diabet Med. 2011; 28(2):20611.

13. Polonsky WH, Fisher L, Guzman S, Villa-caballero L, Edelman SV. Psychological insulin resistance in patients with type 2 diabetes: the scope of the problem. Diabetes Care. 2005; 28(10):2543-5.

14. Nadasen DM, Naidoo M. Patients with type 2 diabetes and difficulties associated with initiation of insulin therapy in a public health clinic in Durban. South African Family Practice. 2012; 54(5):436-40 
15. Ng CJ, Lai PS, Lee YK, Azmi SA, Teo CH. Barriers and facilitators to starting insulin in patients with type 2 diabetes: a systematic review. Int J Clin Pract. 2015; 69(10):1050-70

16. Hosomura N, Malmasi S, Timerman D, Lei V. J, Zhang H , Chang L, Turchin A. Decline of insulin therapy and delays in insulin initiation in people with uncontrolled diabetes mellitus. Diabetic Medicine. 2017; 34(11): 1599-1602

17. Polinski JM, Smith BF, Curtis BH, Seeger JD, Choudhry NK, Connolly JG, Shrank WH. Barriers to insulin progression among patients with type 2 diabetes: a systematic review. Diabetes Educ. 2013; 39(1):53-65
18. Nam S, Chesla C, Stotts NA, Kroon L, Janson SL. Factors associated with psychological insulin resistance in individuals with type 2 diabetes. Diabetes Care. 2010; 33(8):1747-9.

19. Nur Azmiah Z, Zulkarnain AK, Tahir A: Psychological insulin resistance (PIR) among type 2 diabetes patients at public health clinics in federal territory of Malaysia. Int Med J Malaysia. 2011; 10(2):7-12.

20. Abu Hassan H, Tohid H, Amin A. M, Long Bidin M. B, Muthupalaniappen L, Omar K. Factors influencing insulin acceptance among type 2 diabetes mellitus patients in a primary care clinic: a qualitative exploration. Family Practice. 2013; 14:164 